\title{
Linking Performance Related Pay To A Business School's Mission And Objectives
}

\author{
Helen Higson and Jane Filby, Aston Business School, Aston University
}

\begin{abstract}
This paper first analyses the Performance Related Pay (PRP) schemes developed from 1992/3 to 2002/3 in a large Business School in England and then the School's mission and strategic objectives in that period. The PRP schemes changed to include more specific performance indicators and these were increasingly linked to the objectives. The School's resources allocated to PRP increased from $£ 44,000$ in 1992/93 to £355,000 in 2002/3 and from $1.08 \%$ in $1995 / 96$ to $2.37 \%$ of the School's income in $2002 / 3$. As well as examining the changing strategic objectives and PRP schemes, the paper charts the development of the School's reputation and resources and the role which staff motivation via PRP played at different stages. The paper concludes that the PRP scheme was at its most effective when it was clearly linked with the School's strategic objectives, but that the relationship between objectives and motivation may be more complex than apparent from this study. Although the PRP scheme under consideration also applies to academic related staff, this paper concentrates on the effect on academic staff.
\end{abstract}

Key words: performance related pay (PRP), strategic objectives, mission statements, motivation

\section{Introduction}

The Business School in which we undertook this study is located, with three other schools, in a relatively small English university. During the period covered by our study (1992/93 to 2002/3) the School grew from employing less than 60 members of academic staff, teaching 1548 Full Time Equivalent students (FTEs), to $100 \mathrm{mem}$ bers of staff teaching 2325 FTEs. Furthermore, the School's income increased: in 1995/96 it was $£ 8,712,000$ and by $2003 / 4$ it had nearly doubled to $£ 16,276,000$. Its ambition and achievements grew throughout the period, as can be seen from the changing scope of its strategic objectives. The School moved from being a large player (particularly for undergraduate education) in a local market to one growing in all areas of its operations. It gained first a national, then an international reputation, as reflected by external performance indicators. Its research rating rose from 3 to 5 ; its excellent 24/24 teaching rating in the 2001 Quality Assurance Agency (QAA) Subject Review was an increase from 'satisfactory' in 1996. Before 2001 the School did not appear in the top 20 rankings for business and management education in the UK. In 2003 The Times ranked the School as 4th in the UK. At the same time The Economist Which MBA ranked the School's MBA as 4th in the UK, 9th in Europe and 26th in the world.

\section{The context}

The School's mission statements, strategic objectives and PRP schemes must be analysed in the context of the national environment for higher education (HE) during the decade under review. There were major changes in $\mathrm{HE}$, particularly in England but also in Wales and Scotland. Many stemmed from the government's principles for funding HE: plurality, competition, selectivity and accountability. The most important changes were abolition of the line between universities and polytechnics; widening participation to meet the government's target of $50 \%$; growth in quality assurance systems; a decline in the unit of resource and changes in funding arrangements for teaching and research.

In adapting to these changes HE institutions adopted much of the language and many of the practices of the corporate sector, including preparation of mission statements and strategic objectives. Harris (1991 $a$ and $b$ ) suggested that this was brought about because universities had to increase income from non-governmental sources, make more efficient use of their resources and adopt the government's agenda to widen participation and maintain quality. To reach their new goals, universities had to focus more on staff resources and the motivation and efficiency of their employees, using new techniques to set and attain objectives (Schlüter 2004).

HE institutions accordingly prepared mission statements to undertake strategic planning and to signal to all their staff where they were going. Klemm, Sanderson and Luffmann (1991) believed that by setting such statements an organisation could both enhance its external image and motivate its staff. The statements usually included a general philosophy and the intention to develop knowledge, teaching and research, and asserted the specific characteristics of the particular institution. They sought to position institutions in relation to others in the sector and often to the wider community (Davies 1985). Davies and Glaister (1997) analysed the development and use of mission statements in UK business schools, and found that most schools produced a mission statement as part of their strategic planning processes. They also found that external requirements were becoming increasingly important in the writing of these statements. Many schools had only produced them as a response to 
the demands (perceived or otherwise) of external bodies. Davies and Glaister (1997) added that most mission statements included a clear purpose together with some sort of vision for the future, and, in the strategic objectives that flowed from the statements, provided critical success factors against which staff performance could be measured.

If staff performance could be measured against these factors, then it should be possible to link Performance Related Pay (PRP) schemes with mission statements and strategic objectives. Such schemes appear to be linked to goal setting outside the universities: Marsden and French (1998) commented that 'up to half of line managers in the civil service and hospitals believe PRP has raised productivity, improved goal setting, and to a lesser extent raised quality, many staff believe it has improved goal setting.' (p.7).

With a view to examining the links, this paper analyses first the PRP schemes developed from 1992/3 to 2002/3 in the School, then its mission statement and strategic objectives in that period. The statements provided managers and those they managed (in this case mostly academics) with 'evidence and a framework for resource allocation decisions, performance improvement, development needs and opportunities' (Schlüter 2004, p.9). 'In order to motivate a group of academics and lead them towards the university's goals, it is necessary for the institution to be aware of the purpose of its activities and the clear communication of these goals to employees [is essential]. This is especially important in a fastchanging and highly competitive HE environment' (Schlüter 2004, p.10). Crucially, for the ambitions of the School, the statement gave clear signals to all staff about the direction that the School managers wished to take (see Armstrong 2000). Only when the School's mission statement and objectives became more measurable did it seem possible for the PRP scheme to be linked securely to it, but the relationship between PRP and motivation is complex.

The processes of preparing, adopting and disseminating a clear mission statement and strategic objectives do not ensure the desired goals can be attained. As Campbell and Yeung (1999b) said, university managers have to ensure that their staff members are committed to the institution, and Marsden's (2004) work suggests the institution's processes of goal setting and appraisal are also important. The academic leader must create the right conditions to ensure that staff members are encouraged to demonstrate commitment to the institution (Ramsden 1998). Motivational schemes such as PRP must surely be linked to mission and objectives. When the School consciously started to create these links, achievement of the objectives seemed to become more likely. Was the School's success due directly to increased motivation, as first thought, or rather because staff members were increasingly clear about where the School was going?

Schlüter (2004) asked staff in the School about their motivations at work. It was significant that all 20 of her interviewees shared the view that the School's mission was clearly communicated and that staff were aware of the direction in which they were being steered.

According to one interviewee, this was mainly due to messages sent out by the Head of School to staff. Marsden and French (1998) suggested that PRP is a good way of renegotiating work patterns and goals, rather than motivating staff to meet them, and Schlüter (2004) reported that her interviews with School staff indicated that most academics did not change their motivation as a result of PRP but felt it did make clear to them where to focus their energies.

\section{Methods used in this study}

For this study, we compared, through content analysis, the main precepts and financial details of the PRP schemes used by the School with the School's mission statements and strategic objectives (as set out in its strategic plan) for each year 1992/93 to 2002/3. Our research included a statistical analysis of resources allocated annually to PRP, the numbers of staff to whom PRP was awarded and the relative size of the School and its annual turnover (see Table 1). We wanted to identify key trends within the School's awards of PRP when compared with its income. To complement the statistical work, we interviewed (informally, without using a structured interview form) 20 staff and their managers. We also analysed the minutes of the School's Management Committee meetings held during this period. We contextualised our essentially inward-looking methods within the national (and international) environment by reviewing literature on PRP, goal setting and motivation, particularly in the public sector.

\section{Analysis of PRP in the Business School}

In 2002/3 the School allocated $£ 355,000,2.37 \%$ of its annual income, to reward academic, research and academic-related staff via PRP. The School had come a long way since introducing its first PRP scheme, for which it allocated a mere $£ 44,000$ in 1992/3 (see Table 1). Before then, the School was part of a PRP scheme administered centrally in the University: a salary and grading review sub-committee considered nominations, and payments were charged to a $1 \%$ targeted element of the national pay award.

Administering an academic PRP scheme was devolved to schools from 1992/93. The Business School took its PRP scheme very seriously. Its Management Committee decided that year that all performance related payments would be one-off merit payments, not increments to salary. The amount payable to individuals was not fixed, though in fact four levels were used $(£ 575, £ 1150$, $£ 1725$ and £2300). Even at this early stage the link between the PRP scheme and the School's strategic objectives was made obvious when the Head of School reported how the process had been conducted to the Head of Personnel.

The Committee reviewed the scheme every year and it 


\begin{tabular}{|c|c|c|c|c|c|c|}
\hline Academic & $\begin{array}{l}\text { Year Business School's } \\
\text { annual income }\end{array}$ & $\begin{array}{l}\text { s Sums allocated } \\
\text { for PRP }\end{array}$ & $\begin{array}{l}\text { No. of } \\
\text { academic } \\
\text { and research } \\
\text { staff (excluding } \\
\text { professors) }\end{array}$ & $\begin{array}{l}\text { No. of academics } \\
\text { and research staff } \\
\text { rewarded } \\
\text { (excluding } \\
\text { professors) }\end{array}$ & $\begin{array}{l}\text { No. of } \\
\text { academic } \\
\text { related staff }\end{array}$ & $\begin{array}{l}\text { No. of } \\
\text { academic } \\
\text { related } \\
\text { staff } \\
\text { rewarded }\end{array}$ \\
\hline $1991 / 92$ & Not known & $\begin{array}{l}\text { From central } \\
\text { budget }\end{array}$ & Not known & $\begin{array}{l}\text { Centrally } \\
\text { administered }\end{array}$ & Not known & Not known \\
\hline 1992/93 & Not known & $£ 44,000$ & 65 & 28 & 9 & 4 \\
\hline $1993 / 94$ & Not known & $£ 63,572$ & 66 & 25 & 8 & 7 \\
\hline $1994 / 95$ & Not known & $£ 64,929$ & 70 & 25 & 9 & 5 \\
\hline $1995 / 96$ & $£ 8,712,000$ & $£ 94,576$ & 77 & 11 & 12 & 3 \\
\hline $1996 / 97$ & $£ 8,986,000$ & $£ 83,975$ & 81 & 18 & 15 & 7 \\
\hline $1997 / 98$ & $£ 8,556,000$ & $£ 86,514$ & 67 & 55 & 14 & 12 \\
\hline 1998/99 & $£ 9,470,000$ & $£ 100,149$ & 66 & 47 & 14 & 13 \\
\hline $1999 / 00$ & $£ 10,882,000$ & $£ 100,454$ & 66 & 50 & 15 & 13 \\
\hline $2000 / 01$ & $£ 10,911,000$ & $£ 200,000$ & 65 & 58 & 17 & 14 \\
\hline $2001 / 02$ & $£ 13,316,000$ & $£ 300,000$ & 66 & 65 & 19 & 16 \\
\hline $2002 / 03$ & $£ 14,959,000$ & $£ 355,000$ & 85 & 74 & 20 & 18 \\
\hline
\end{tabular}

\section{Table 1: PRP statistics in the Business School, 1991/92-2002/03}

increased in detail and specificity. Table 1 sets out first the sum allocated for PRP, then the number rewarded through PRP of academic and research staff (excluding professors), and of academic related staff. The total staff numbers in these categories also appear for each year, and the annual School income (we were able to obtain the annual income of the School only from 1995/96.

From these figures we were able to calculate that the proportion of income allocated to PRP more than doubled, from $1.08 \%$ in $1992 / 93$ to $2.37 \%$ in $2002 / 3$. PRP and the incentives it provided seem to us to have been regarded as increasingly important by the School's senior management. Given the School's substantial achievements during this period, it appears that the managers believed that PRP was important in achieving its strategic objectives.

We also calculated that in real terms (taking no account of inflation or increases in the School's annual wage bill), while its income doubled between 1995/96 and 2002/3, the money allocated to PRP increased by more than $700 \%$. This was only partly due to the fact that the number of staff increased, adding to the total resources available from the targeted $1 \%$ of the wage bill. The number of academic staff has risen from 65 in 1992/3 to 85 in 2002/3 (a 30\% rise). The total number of staff (both academic and academic-related) increased by $41 \%$ from 74 to 105 from $1992 / 3$ to $2002 / 3$.

Deliberate decisions by the managers created greater incentives for staff as the School's ambitions increased. The School needed to introduce these incentives, beyond those that other business schools offered in a very competitive environment, to carry out its bold strategies and become a leading business school in Europe. By 2002/3 the average payment per person was about $£ 4,000$ with a maximum of $£ 8,000$. Our research could not find any evidence, however, that this increase in incentives had had an effect on the recruitment and retention of staff, although there had been a low staff turnover. None of the staff we interviewed had come to the School because of PRP and some said that they did not know about the scheme until they arrived.

Malkinson's (2002) civil service report concluded that PRP does not motivate public sector workers. Our interviews with the School's Head revealed the same view. 'There was an expectation that PRP would have an effect on motivation... but there is no evidence that our PRP attracts and retains staff. If you are a conscientious academic you do it [meet strategic objectives] anyway.' Additionally, he indicated that pay scales in UK business schools are such that there is much more flexibility to recruit at the necessary pay levels. If there is a retention issue in the School, it has the power to match pay rates elsewhere without much trouble.

Our analysis of the proportion of staff awarded PRP showed a correlation between the numbers awarded and the different phases of links between strategic objectives and the PRP schemes. The number of academic staff being awarded PRP annually rose by $165 \%$ (187\% for all staff), over a 10 year period, whereas there was only a $30 \%$ increase in academic staff employed ( $41 \%$ for all staff). Year on year the proportion of academic staff being awarded PRP increases from $43 \%$ of academic staff employed in 1992/3, drops to around 
$20 \%$ in 1995-1997 (below 15\% in 1995/96), and dramatically increases to between 87 and $98 \%$ within the last three year period. This dramatic increase coincides with a change of Head of School and a change in the form, if not the content, of strategic objectives, in that they were more clearly specified and quanitified.

The increase in the number of staff being awarded PRP also links in two ways with Marsden's (2004) findings that PRP is a major tool to increase productivity. Firstly, at the time of employment most renegotiation of performance norms occurs. People who do not like the terms of the contract (PRP or strategic objectives) go elsewhere. New staff members have to buy in to the PRP and strategic aims. Secondly, there is also an effect on current staff. Although PRP may not have been a major incentive, our interviews with managers and staff showed that they 'liked the pat on the back': they liked the bonus which re-aligning their current teaching and research activity gave them. Furthermore, they liked being at a successful institution.

\section{Analysis of the School's mission and strategic objectives}

We analysed the School's mission and strategic objectives and how these changed up to 2002/03. In 1991/92, the last year of the University-wide PRP scheme, the Schools' mission was stated as:

* To make an incisive contribution through Research, Scholarship and Teaching to shaping organisational strategies for creating wealth and realising human potential to the benefit of society in general and the academic, business and professional communities in particular.

* To create and extend knowledge, to question existing practices and beliefs, and to disseminate the findings of such research and scholarship to the academic, business and professional communities.

* To develop further interdisciplinary research and teaching drawing on the intellectual strategies of the functional specialisms of management and the disciplinary regimes of the social sciences.

* To become a benchmark for best practice in Research, Scholarship and Teaching amongst business schools in the New Europe.

This mission statement was supported by six objectives:

1 To strengthen academic leadership by increased appointments of senior staff in core management disciplines, together with further appointments of associated faculty designed to restore a balanced portfolio of academic staff, and an overall improvement in the full-time staff/student ratio.

2 To reinforce mechanisms of quality assurance intended to deliver teaching programmes consistent with its mission.

3 To orient its activity more closely to the New Europe of the 21 st century, utilising research expertise demonstrating scholarship and achieving a teaching focus which in a rich and diverse manner reflects changing economic and social values and processes.

4 To create and extend knowledge through the Research Institute by identifying and addressing key global and regional themes of the 21st century business and management agenda.

5 To infuse teaching with the distinctive essence of the School's established tradition in inter-disciplinary research. To exploit the School's demonstrated success in inter-disciplinary international studies with a strong European content in order to be recognised as a leading European Business School.

6 To provide a significant cash flow based on premium fee income by which surpluses generated may be used to fund continuing improvement in the competitive position of the School.

Starting from this statement (which was unchanged for the next year, 1992/93, but see Appendix 1 for changes thereafter) we charted the development of the School and the growth in its ambitions, as well as monitoring the School's growth via the statistical analysis of PRP data. Like the PRP schemes, the strategic mission and objectives appear to go through three distinct phases (see Appendix 1 for the actual statements), each linked with a different style of management under the Head of School or Dean and the Management Committee. In the first phase the mission and objectives were much less detailed than those developed more recently. Although the Management Committee minutes confirm links existed between the two, PRP criteria were very basic. From 1989 to 1991, for example, the mission was very general and the objectives were not focused towards measurable goals. Compare, for example, 'to introduce more efficient and effective learning opportunities for students' (1990/91) with 'to continue to achieve an excellent result in QAA exercises and maintain or gain full accreditation ...' (2000/01). By 1991/92 the mission statement had become very complex. The objectives may not have been very realistic at the time, but that statement set out concisely the position which the School achieved by 2002/03: 'to become a benchmark for the best practice in research, scholarship and teaching amongst business schools in the New Europe.'

Furthermore, the early strategies appear to have been somewhat aspirational - a wish list rather than a careful progression to desirable and achievable aims. Back in 1989/90, for example, the School hoped to 'capitalise' on international strengths that would 'put it in a unique position to take a leading role in European education in the 1990s.' The presence of an objective relating to internationalisation is an interesting indication of the School's outlook throughout the period under review and it is possible to chart the School's growth in size and ambition via its international objectives. The international dimension was evident in the early years, and as the objectives became more realistic and more planned, the international aspirations temporarily disappeared. When international objectives reappeared there was a more 
relaxed approach. International strategies were expressed as reachable, measurable targets, rather than aspirational themes.

The School was much smaller at the beginning of the review period and its national and international profiles were less strong. As the School grew the strategic objectives were expressed in more confident yet practical terms. Earlier some of the School's problems were evident in its objectives. Back in 1989/90 they indicated that recruitment of senior and other staff was a priority 'to restore a balanced portfolio.' Financial and infrastructure preoccupations came to the fore in 1990/91: the development of the Local Area Network (LAN) and Computer Assisted Learning (CAL), physical accommodation for postgraduate and post-experience students as well as expanding the School's income from non-funding council sources. Staffing was still a problem in 1992/3, when PRP was apparently not being used overtly to recruit or retain staff. The amount allocated to PRP and the number of awards to staff were still low compared to the number of staff.

In the second phase, the middle years, the School appeared to move away from a strong international ambition: inward-looking issues featured in the objectives, perhaps reflecting financial stringencies in the national HE environment. There were also indications that the School was experiencing financial constraints as reflected in the PRP schemes (see 1995/96 and $1996 / 97$ in Table 1). The number of awards made to staff and the amount of resource allocated for this period did not increase. In 1995/96 the Head of School made this very apparent in his PRP announcement, 'In view of the University's financial position I made a decision that awards be restricted to a few in number... I used information from the load model to select staff on the basis of outstanding performance'.

In 1992/93, PRP was devolved to schools, but the School's mission did not immediately change as a result. At this stage there was no link between mission, objectives and PRP, and no specific guidelines on how PRP should be allocated. The Management Committee did not make this link in its minutes. All the PRP factors were expressed in terms of the individual rather than linked to any institutional good or goal. In theory, an individual could be rewarded the maximum amount of PRP without taking the School any further towards its goals. PRP was not being used even for 'renegotiation of performance norms' (Marsden 2004, p.351), rather the opposite. At this time 28 out of 65 staff received PRP awards.

By 1993/94 the staffing objectives had gone and the PRP criteria were no clearer, but this year saw the start of a more focused mission statement and objectives that could be linked to a PRP scheme. By 1994/95, PRP was consciously linked to the School's strategic direction 'on the basis of outstanding performance in areas which support the strategic direction of the School', although there seems to have been little consultation in allocating PRP awards to an explicitly exclusive group of staff. The most notable feature of the PRP awarded during these two years is the deliberately exclusive nature of the awards.

In 1996/97 the scheme was still exclusive but there was greater transparency in the published intention that $20 \%$ of staff should be awarded PRP of fairly large amounts $(£ 2,500)$. Although there was no definition of what the required 'exceptional performance' should consist of, it was easier for staff to work out what they needed to achieve because the objectives were now very focused: just two relating to research and teaching. Though the link between PRP and objectives was not yet explicit, it was emerging.

Finally, in the third phase, from 1998, the greatest changes in PRP and the objectives took place. Firstly, the policy became explicitly inclusive; secondly, the funds allocated grew more than proportionately to increases in staff, and, thirdly, the link between PRP and strategic objectives became clearer, possibly because the importance of how the process was managed was realised (cf. Marsden 2004, p.366). Management Committee minutes show that the PRP scheme was being reviewed at a strategic level at least two or three times a year. There was convergence of PRP criteria and strategic objectives. In 1998/99 for the first time PRP criteria were linked in particular to what developed as the two main objectives - teaching quality and research excellence. Operation of the scheme did not rely on the Head of School's opinion based on consultation with senior staff alone. Instead, a nomination system was introduced, using data from qualitative and quantitative sources, including feedback from students and other customers.

By 2002/03, when the amount of money for PRP was nearly $£ 400,000$ and the number of staff over 100 , the specificity of both the strategic objectives and the PRP scheme was conspicuous. Staff now knew in advance exactly what they needed to achieve in order to be awarded PRP - how many journal articles they had to publish in which publications, what standard of teaching they had to achieve and what citizenship activities they had to undertake. The School had clearly identified that linking the PRP scheme with the objectives took some management. Schlüter (2004) confirmed through her interviews that qualitative data from various sources and quantitative data from the School's work load model were indeed part of the PRP process. The mission overtly mentioned the importance of motivating and encouraging staff to meet all the strategic objectives, and in doing so, made the role of PRP more important and deliberately linked with the objectives. Words such as 'recognition', 'efforts', and 'thank you for special efforts' arrived in the scheme. Despite these wording changes, the researchers found no direct evidence that staff felt better motivated, or were retained better.

\section{Conclusion}

As the resources allocated to PRP grew the PRP criteria 
became more specific and transparent, and so did the strategic objectives. The PRP process was managed more. Indeed, as the School's mission and objectives became more specific and more challenging, the operation of PRP mirrored them. It became more difficult for staff to meet the criteria (e.g. by 2002/03 no PRP award was made to staff who did not exceed research thresholds) but PRP became more inclusive in that the scheme was set up for more staff to gain awards. This was an acknowledgement that in order to meet the ambitious strategic objectives successfully, everyone in the School had to 'buy into the journey' and have clear signals about where they were going. Interviews in the School revealed that those who objected most to the PRP scheme had not 'played the game' in carrying out the tasks that were important to the School. Many of these people were no longer employed by the institution by 2002/03.

As the PRP criteria became more specific and more linked to specific objectives there had to be more measurement, triangulation and checking of data. Preparation for PRP decisions became a time consuming process. Data had to be robust and criteria transparent. The School did not, however, link certain PRP points with specific student feedback averages. The School drew back from this, but still took general student feedback into account. An appeals mechanism was established for staff.

A certain level of PRP seemed to be regarded as optimal by the end of the period we studied. The value of the awards was seen as significant enough to attract and motivate staff. In future the total budget will probably increase more or less in line with growth in staff numbers. The School's managers believe that other motivations, such as its culture and the time to pursue research activities, must also be available and that money alone will not motivate staff to meet the School's objectives. PRP is one way among several in which the School manages its environment.

Was the story we tell similar to that in other UK Business Schools? Some may be managed less or operated more collegially. Some may experience a period of expansion, as we did; in a period of consolidation or of contraction PRP might have to serve different ends. How fair is PRP? How can it remain transparent and appropriate to the strategic objectives? Who should be involved in the PRP consultation and in the objectivesetting process? Should it be led by the Head of School or owned by the staff? And how could PRP be changed to be an effective recruitment or retention tool? These are questions that deserve further study.

\section{Acknowledgement}

The authors were fortunate to have access to the Minutes of the Business School's Management Committee for the period under review.

\section{References}

Allen, M. 1988, The Goals of Universities, SRHE and Open University Press, Buckingham.

Armstrong, M. 2000, Performance Management: Key Strategies and Practical Guidelines, 2nd edition, Kogan Page, London.

Armstrong, M. 2002, Employee Reward, 3rd edition, CIPD, London.

Ball, C. \& Price, H. (ed) 1989, Higher Education into the 1990s: new dimensions, The Society for Research into Higher Education and Open University, Buckingham.

Brown, T.C. \& Latham, G.P. 2000, 'The Effects of Goal Setting and Self-Instruction Training on the Performance of Unionized Employees', Relations Industrielles, 55, 1, pp.80-95.

Campbell, A. \& Yeung, S. 1991a, 'Brief case: mission, vision and strategic intent', Long Range Planning, 24, 4, pp.145-147.

Campbell, A. \& Yeung, S. 1991b, 'Creating a Sense of Mission', Long Range Planning, 24, 4, pp.10-20.

Davies, J. 1985, 'Institutional Mission and Purpose', in Lockwood, G. and Davies, J. (eds.) Universities: The Management Challenge, SRHE\& NFER-Nelson, Windsor, pp.80-101.

Davies, S. \& Glaister, W. 1997, 'Business School Mission Statements: the Bland Leading the Bland?', Long Range Planning, 30, 4, pp.594-604.

Ford, P. (ed.)1996, Managing Change in HE: a Learning Environment Architecture, The Society for Research into Higher Education and Open University.

Harris, M. 1991a, Cost-effectiveness and efficiency in universities: a British perspective, paper to the Conference of Executive heads, the Association of Commonwealth Universities, New Delhi.

HMSO 1991, Higher Education: a new framework, London, May.

Higher Education Funding Council for England 2001, Rewarding and Developing Staff in Higher Education, March 01/16.

Klemm, M., Sanderson, S. \& Luffmann, G. 1991, 'Mission Statements: Selling Corporate Value to Employees', Long Range Planning, 24, 3, pp.73-78.

Locke, E., \& Latham, G. 1990, A Theory of Goal Setting and Task Performance, Prentice Hall, Englewood Cliffs.

Malkinson, J. (Chair) 2000, Incentives for Change: Rewarding Performance in National Government Networks, Public Services Productivity Board, HM Treasury, London.

Marsden, D. 2004, 'The role of performance-related pay in renegotiating the "effort bargain" the case of the British public service', Industrial and Labor Relations Review, 57, 3, pp.350-370. 
Marsden, D \& French, S. 1998, 'What a Performance:

Performance Related Pay in the Public Services'

Centre for Economic Performance Special Report, London School of Economics.

Miller, H. \& Higson, H. 1999, Managing Diversity: Managing Academics, paper for the British Academy of Management Conference, Manchester.

Murlis, H. \& Hartle, F. 1996, 'Does It Pay to Work in Universities?' in Cuthbert, R. (ed.), Working in Higher Education, SRHE \& Open University Press, Buckingham, pp.46-57.

Pearce, J. 1982, 'The Company Mission as a Strategic Tool', Sloan Management Review, 23, 3, pp.15-24.

Prendergast, C. 1999, 'The Provision of Incentives within Firms', Journal of Economic Literature, 37, 1, pp.763.

Ramsden, P, 1998, Learning to Lead in Higher Education, RoutledgeFalmer, London.

Shipton, H., Fay, D., West, M., Patterson, M \& Bird, K. 2005, 'Managing People to Promote Innovation', Creativity and Innovation Management, 14, 2, pp.118-127.

Schlüter, S. 2004, Managing Staff Performance in British HE: A case study, unpublished MSc thesis, Trier University.

Trow, M. 1994, 'Managerialism and the Academic Profession: Quality and Control', Quality Support Centre, Higher Education Report No.2, Open University Press, Buckingham. 


\section{Appendix I: The School's Mission and Objectives linked to the PRP scheme, 1993/1994 to 2002/03}

\section{$1993 / 94$}

\section{Mission}

As a leading Business School, to produce excellent scholarship, research and teaching in areas relevant to management, business and organisations in both the private and public sectors.

\section{Objectives}

To provide customers with effective preparation for involvement in managerial, organisational and business activities requiring high level analytical skills and specialised understanding of the technological, social, legal, political and economic environment.

To develop an improved interdisciplinary understanding of the effective operation of individuals and organisations, based upon stength in-depth across the social sciences and using close links with professional and managerial practitioners.

To advance knowledge through in-depth interdisciplinary research, relevant to the understanding of organisations, environments and best management practices, and to disseminate the findings of this research within relevant academic business and professional communities.

To develop and maintain a balanced set of sources of revenue at a level which allows the School to achieve its academic objectives on a financially sound basis.

\section{$1994 / 95$}

\section{Mission}

No change in mission or objectives

\section{Mission}

No change in mission or objectives

\section{Advice to those making recommendations}

In any recommendation you should cover the following points: The activity in which the individual has distinguished themselves in the year under review.

Why the individual is considered to be deserving of recognition. Whether a discretionary increment or one-off merit payment should be made.

The amount of money that you propose the individual should be paid if a one-off merit payment is being recommended.

\section{Advice to those making recommendations}

The criteria used for the review:

Outstanding performance with particular emphasis on student support (visits, resource packs, on-time marking etc)

\section{$1995 / 96$}

\section{Advice to those making recommendations}

"In view of the University's financial position I made a decision that awards should be restricted to a few in number and thus at least maintain the individual value of previous years awards. I used information from the load model to select staff on the basis of outstanding performance in areas which support the strategic direction of the School, and then consulted with the Directors and Convenors to confirm." (Head of School) 


\section{6/97}

\section{Mission}

No change in mission

\section{Objectives}

The School is committed to the dual objectives of: Attaining a teaching quality assessment rating of $20+$ points

Attaining a 5 research rating.

\section{Mission}

To continue to develop as an agile, progressive and leading European business school, with an international reputation for integrated rigorous research, practical relevance and teaching quality, excellent students and staff working in a supportive, nurturing and motivating environment.

\section{Objectives}

To achieve a research rating of 5 in the 2001 Research Assessment Exercise (RAE) and $5^{\star}$ thereafter.

To achieve at least 23 points (out of a possible 24) in the next business Teaching Quality Assessment (TQA) and maintain full accreditation of programmes by AMBA and ESRC and professional bodies.

To increase the income per FTE student by increasing the income from UG overseas students, PG and MDC to exceed the UG HEFCE teaching and home tuition income.

To keep the School's unallocated central costs to less than 2 per cent of turnover each of it's programmes (UG,PG and MDP) and teaching groups paying their contribution to the University's devolved overheads.

To achieve surpluses beyond the University's contribution to fund strategic initiatives and increased Performance Related Pay (PRP) flexibility.

\section{Advice to those making recommendations}

PRP should take the form of one-off merit awards only. That $20 \%$ of academic and ACR staff should be targeted for awards (ie. About 20 awards).

That the average value of the awards should be $£ 2,500$.

That awards should be made for staff who have displayed an exceptional performance during this period.

\section{$1998 / 9$}

\section{Advice to those making recommendations}

This year PRP for academic and ACR staff will operate in the School on an inclusive basis rather than an exclusive basis. The fund will be split in three ways:

Research: $£ 500$ to go to each member of staff who is currently RAE submittable, or in the case of new staff, who is making good progress towards being submittable. The Director of Research and the subject group convenors will be asked to name all those who reach these thresholds.

Teaching: $£ 500$ to go to each memember of staff who has performed by TQA standards in their teaching duties (this is full-time and part-time academic staff not sessionals). The programme directors and the subject group convenors will be asked to name all those who reach this threshold.

Meritorious performance: To be awarded in values of $£ 1,000$ and £2,000. To go to each member of staff who has demonstrated an outstanding contribution, or a meritorious performance in any area of teaching, research, administration, or good citizenship. Subject group convenors, directors of programmes and other managers of academic and academicrelated staff will be asked to submit nominations.

Principles: There will be three guiding principles behind the awards:

A recognition and thank you for the efforts made over the year

A recognition and thank you for special efforts made during the year.

All awards will be subject to a qualifying criteria of "good citizenship". 


\section{$1999 / 2000$}

\section{Mission}

No change

No change

No change

No change

\section{Advice to those making recommendations}

Research: $£ 500$ to go to each member of staff who is currently RAE submittable, or in the case of new staff, who is making good progress towards being submittable. The Director of Research and the Subject Group Convenors will be asked to name all those who have reached these thresholds.

Teaching: $£ 500$ to go to each member of staff who has performed to TQA standards in their teaching duties. The Programme Directors and the Subject Group Convenors will be asked to name all those who have reached this threshold.

Meritorious performance: To be awarded in values up to $£ 2,000$. To go to staff who have demonstrated an outstanding contribution, or a meritorious performance in any area of teaching, research, administration or good citizenship. Subject Group Convenors, Directors of programmes and other managers of academic staff will be asked to submit nominations.

Principles: There will be three guiding principles behind the awards:

A recognition and thank you for the efforts made over the year

A recognition and thank you for special efforts made during the year.

All awards will be subject to a qualifying criteria of "good citizenship".

\section{0/200I}

\section{Mission}

To continue to develop as an agile, progressive and leading European business school, influencing policy and practice in organisations locally, nationally and internationally, with a reputation internationally for integrated rigorous research, practical relevance and teaching quality With excellent students and staff working in a supportive, nurturing and motivating environment.

\section{Objectives}

To achieve a research rating of 5 in the 2001 Research Assessment Exercise (RAE) and $5^{\star}$ thereafter.

To continue to achieve an excellent result in QAA exercises and maintain or gain full accreditation of programmes by AACSB, AMBA, EQUIS, ESRC and professional bodies.

To increase the income per FTE student by 1) balancing HEFCE clawback and fees-only UG students 2) develop band $C$ teaching and 3) increasing the income from UG overseas students, $P G, M D P$ and MDC.

\section{Advice to those making recommendations}

Research: An award to go to each member of staff who was submitted for RAE this year. The Director of Research is asked to name all those who have reached this threshold. Value $£ 500$

Teaching: An award to go to each member of staff who has performed to QAA standards in their teaching duties. Programme Directors and the Subject Group Convenors are asked to name all those who have reached this threshold. Value $£ 500$

Meritorious performance: Merit awards to go to staff who havedemonstrated an outstanding contribution or a meritorious performance in any area of teaching, research, administration or good citizenship. Subject Group Convenors, Directors of Programmes and other managers of academic staff are asked to submit nominations.

Value $£ 1,000$ 
To keep the School's unallocated central costs to less than 2 per cent of turnover each of its programmes (UG, PG and MDP) and teaching groups paying their contribution to the University's devolved overheads.

To achieve surpluses beyond the University's contribution to fund strategic initiatives and increased Performance Related Pay (PRP) flexibility.

\section{Exceptional performance:}

A merit award to go to those staff who are perceived by staff and students as being exceptional teachers. Programme Directors and Subject Group Convenors are asked to name those who have reached this level.

Value £2,000.

A merit award to go to those staff, who had at least two of their four publications submitted for RAE, at international standing (measured against externally agreed criteria). The Director of Research is asked to name those who have reached this level.

Value $£ 2,000$

\section{Principles:}

There are three guiding principles behind the awards:

A recognition and thank you for special efforts made over the year.

A recognition and thank you for special efforts made during the year.

All awards will be subject to a qualifying criteria of "good citizenship".

\section{$2001 / 2$}

\section{Mission}

To continue to develop as an agile, progressive and leading European business school Influencing policy and practice in organisations locally, nationally and internationally

\section{Advice to those making recommendations}

PRP for academic and ACR staff will operate in the School on the same basis as last year, that is, on an inclusive basis. It will be in the form of merit awards. The fund will be split in four ways:

With a reputation internationally for integrated rigorous research, practical relevance and teaching quality

With excellent students and staff working in a supportive, nurturing and motivating environment.

\section{Objectives}

To achieve a research rating of $5^{\star} \mathrm{A}$ in the 2006 Research Assessment Exercise (RAE).

To continue to achieve an excellent result in QAA exercises and maintain or gain full accreditation of programmes by AACSB, AMBA, EQUIS, ESRC and professional bodies.

To increase the income per FTE student by 1) developing band $C$ teaching 2 ) increasing the income from UG overseas students 3 ) increasing the premium priced management development activities in PG, MDP and MDC and 4) maintaining tradition of access to programmes by disadvantaged groups.

To keep the School's unallocated central costs to less than 2 per cent of turnover each of its programmes (UG, PG and MDP) and teaching groups paying their contribution to the University's devolved overheads.

To achieve surpluses beyond the University's contribution to fund strategic initiatives and increased Performance Related Pay (PRP), accommodation quality and strategic flexibility.
Research: An award to go to each member of staff who is currently RAE submittable, or in the case of new staff, who is making good progress towards being submittable.

Teaching: An award to go to each member of staff who has performed to QAA standards in their teaching duties.

Meritorious Performance: Merit awards to go to staff who have demonstrated an outstanding contribution, or a meritorious performance in any areas of teaching, research, administration or good citizenship. 
Refine and ensure that a supportive, nurturing and motivating organisation is able to cope with the increased scale, sophistication and demands of the larger business school, while providing an excellent service to students and the front line providers of teaching and research.

\section{Mission}

No change

No change

\section{Exceptional performance:}

a) Teaching - a merit award to go to those staff who are perceived by staff and students as being exceptional teachers.

b) Research - A merit award to go to those staff who have at least two of their publications at international standing, measured against externally agreed criteria.

There are three guiding principles behind the awards:

A recognition and thank you for the efforts made over the year.

A recognition and thank you for special efforts made during the year.

All awards will be subject to a qualifying criteria of "good citizenship".

\section{$2002 / 3$}

\section{Advice to those making recommendations}

\section{Criteria}

Research output and publications (assessed over the previous 4 calendar years)

Research output of national standing (RAE4) At least four papers in refereed academic journals of national standing (1 point)

Research output of part international standing (RAE5). At least two papers in refereed academic journals of international standing together with at least two papers in refereed academic journals of national standing (2 points) Research output of full international standing (RAE5*). At least four papers in refereed academic journals of international standing (3 points)

Teaching and Learning Enhancement (only added if research output is at least National standing).

Good and effective teaching as identified by student feedback and the views of programmes, coupled with regular attendance at exam boards and student consultative committees. Recognition will be given for those with high teaching loads (1 point) Very good and effective teaching as identified by student feedback and views of programmes. Examples include teaching evaluations significantly above average ratings, and innovation in pedagogical approaches.

Outstandingly good and effective teaching and contribution to teaching programmes. Examples include entrepreneurship or innovation in programmes, courses or methods.

\section{Outstanding Contribution}

Rare and exceptional contribution to the well being of the School, its staff and students, during the year or over a longer period (Up to 3 points)

Examples include:

Major academic achievement such as completing $\mathrm{PhD}$ Achievement of significant teaching qualification such as ILT certificate Exceptional contribution to student well being Award of a significant new research grant Major role in organising international conference 
Gaining top prize at national conference or prize at international conference

Holding an elected post in a significant national or international academic body

Holding a post in a prestigious institutions (e.g. ESRC, EPSRC, Government Committees

Editorship of an international journal

Publication in one of the very few top international journals in the discipline. 